\title{
PENGARUH PENERAPAN ABSENSI SIDIK JARI (FINGERPRINT) DAN DISIPLIN KERJA PEGAWAI NEGERI SIPIL DALAM MENINGKATKAN KINERJA PEGAWAI PADA BADAN PENGELOLA KEUANGAN DAN ASET DAERAH KABUPATEN BUNGO
}

\author{
Muhammad Asman, Novi Darmalia \\ Program Studi Manajemen Fakultas Ekonomi \\ Universitas Muara Bungo
}

\begin{abstract}
ABSTRAK
Tujuan penelitian ini adalah untuk mengetahui dan menganalisis pengaruh penerapan absensi sidik jari (Fingerprint) dan disiplin kerja pegawai dalam meningkatkan kinerja pegawai pada Badan Pengelola Keuangan dan Aset Daerah Kabupaten Bungo. Penelitian ini merupakan jenis penelitian Deskriptif Kuantitatif. Populasi dalam penelitian ini adalah Aparatur Sipil Negara (ASN) Badan Pengelola Keuangan dan Aset Daerah Kabupaten Bungo. Yang berjumlah 40 orang. Metode pengumpulan dalam penelitian ini adalah wawancara, kuesioner dan studi dokumentasi. Metode analisis data menggunakan metode deskriptif dan analisis Regresi Linier Berganda $Y=\mathbf{- 1 1 , 1 7 7 ~ + ~ 0 , 3 1 1 ~ X 1 ~ + ~ 1 , 8 7 8 ~ X 2 ~ + ~ e ~}$

Hasil penelitian menunjukkan bahwa variabel Penerapan Absensi Sidik Jari (Fingerprint)mempunyai pengaruh positif namun tidak signifikan sementara variabel disiplin kerja mempunyai pengaruh positif dan signifikan terhadap Kinerja Pegawai Pada Badan Pengelola Keuangan dan Aset Daerah Kabupaten Bungo. Hal ini dapat dilihat Uji signifikan Parsial (Uji t) dan Koefisien Determinasi nilai $R$ Squaresebesar 0.610 atau $61,0 \%$ dapat dijelaskan oleh kedua variabel bebas sebesar $61,0 \%$ sedangkan sisanya sebesar $39,0 \%$ dipengaruhi oleh faktor lain yang tidak diteliti
\end{abstract}

Kata kunci : Absensi Sidik Jari (Fingerprint), Disiplin Kerja, Kinerja Pegawai

\section{PENDAHULUAN}

Dalam Era Globalisasi ini, dapat kita lihat bahwa perkembangan ilmu pengetahuan dan teknologi secara tidak langsung, mengubah cara kita hidup dan bekerja. Perubahan teknologi telah menjadi sumber penting dari ketidakpastian lingkungan yang dihadapi organisasi atau instansi, perubahan teknologi ini dapat juga memungkinkan para pimpinan untuk mengkoordinasikan tatanan kerja para pegawai dengan cara lebih efisien dan efektif.
Sumber daya manusia adalah potensi manusiawi yang melekat keberadaannya pada seseorang yang meliputi potensi fisik dan non fisik.Salah satu fungsi dari manajemen sumber daya manusia adalah kedisiplinan.

Kedisiplinan merupakan fungsi terpenting dalam manajemen sumber daya manusia, karena semakin baik disiplin pegawai, semakin tinggi pula prestasi kerja.Disiplin kerja dapat dilihat sebagai sesuatu yang besar manfaatnya, baik bagi kepenting`an organisasi atau instansi maupun bagi 
para pegawai. Bagi organisasi atau instansi adanya disiplin kerja akan menjamin terpeliharanya tata tertib dan kelancaran pelaksanaan tugas, sehingga diperoleh hasil yang optimal.

Kedisiplinan berkaitan dengan kinerja pegawai tersebut, terlihat dari hasil pekerjaannya yang sudah sesuai atau tidak dengan standar kinerja yang telah ditentukan. Tentu tidak mudah bagi pegawai untuk mencapai kinerja yang diharapkan oleh organisasi atau instansi apabila tidak didukung oleh kedisiplinan kerja yang kondusif di organsiasi atau instansi. Upaya-upaya dalam peningkatan kinerja Pegawai merupakan tantangan bagi sebuah organisasi atau instansi. Banyak penelitian serta pendapat para ahli mengenai faktor-faktor yang mempengaruhi Kinerja Pegawai, salah satunya adalah menurut A. Dale Timple (Mangkunegara,2009:15) adalah sebagai berikut :

1. Faktorinternal (disposisional) yaitu faktor yang berhubungan dengan sifat-sifat seseorang.

2. Faktor eksternal yaitu faktoryang mempengaruhi kinerja seseorang yang berasal dari lingkungan seperti perilaku, sikap, dan tindakan-tindakan rekan kerja, bawahan atau pemimpin, fasilitas kerja dan iklim organisasi.

Sistem absensi merupakan salah satu bentuk pengawasan kedisiplinan yang sudah sejak lama diterapkan oleh organisasi atau instansi pemerintahan.Sistem informasi kehadiran Pegawai Negeri Sipil atau Aparatur Sipil Negara pada instansi pemerintahan umumnya masih menggunakan sistem informasi manual sehingga penegakan disiplin Pegawai Negeri Sipil atau Aparatur Sipil Negara khususnya masuk kantor dan pulang kantor belum maksimal. Selain itu, kemungkinan terjadinya titip menitip absen antar pegawai sangat besar.

Dengan mengunakan alat ini, absensi yang direkapitulasi setiap sebulan sekali akan dapat dengan mudah diketahui pelanggaran jam kerja maupun keterlambatan yang telah dilakukan oleh para pegawai, dikerenakan dengan absensi sidik jari ini sulit dilakukan manipulasi data.

Peraturan Pemerintah Nomor 53 Tahun 2010 tentang Disiplin Pegawai Negeri Sipil atau Aparatur Sipil Negara merupakan tonggak aturan penerapan kedisiplinan bagi seluruh Pegawai Negeri Sipil atau Aparatur Sipil Negara dalam lingkup Negara Kesatuan Republik Indonesia.

Secara keseluruhan peraturan tersebut merupakan aturan-aturan mengenai kedisiplinan Pegawai Negeri Sipil atau Aparatur Sipil Negara yang berisikan ketentuan umum, kewajiban, larangan, dan hukuman disiplin Pegawai Negeri Sipil atau Aparatur Sipil Negara dalam rangka untuk meningkatkan citra, kerja maupun kinerja instansi pemerintahan menuju kearah profesionalisme dan menunjang terciptanya pemerintahan yang baik dan dipergunakan sebagai pedoman atau acuan dalam melaksanakan tugas baik manajerial maupun operasional diseluruh bidang tugas dan unit organisasi atau instansi pemerintah secara terpadu.

Berdasarkan observasi, penerapan absensi sidik jari 
(Fingerprint) diBadan Pengelola Keuangan dan Aset Daerah (BPKAD) Kabupaten Bungo sangat efektif digunakan bagi Pegawai, karena penggunaan absensi sidik jari (Fingerprint) sangat mudah dan tidak dapat di manipulasi.

Namun dalam rangka untuk meningkatkan disiplin Pegawai di Badan Pengelola Keuangan dan Aset Daerah (BPKAD) Kabupaten Bungo, penerapan absensi sidik jari (Fingerprint) tersebut belum berjalan dengan efektif, karena masih ada ditemukan pelanggaran yang dilakukan oleh Pegawai di Badan Pengelola Keuangan dan Aset
Daerah Kabupaten Bungo, seperti Pegawai yang meninggalkan kantor saat jam kerja, datang dan pulang tidak sesuai jam kerja, datang ke Kantor untuk absensi kemudian pergi meninggalkan kantor, serta kurangnya kesadaran Pegawai atau Karyawan untuk meningkatkan pelayanan yang optimal.

Berdasarkan Sumber Data dari Kantor Badan Pengelola Keuangan dan Aset Daerah Kabupaten Bungo bahwa Pegawai Negeri Sipil atau Aparatur Sipil Negara berjumlah 40 (Empat puluh) Orang, dalam hal ini dapat dilihat sebagai berikut :

\section{Jumlah Pegawai Negeri Sipil}

Badan Pengelola Keuangan dan Aset Daerah Kabupaten Bungo

\begin{tabular}{|c|c|c|}
\hline No & Jabatan & Jumlah \\
\hline 1. & Kepala Badan & 1 \\
\hline 2. & Sekretaris & 1 \\
\hline 3. & Kepala Bidang Anggaran & 1 \\
\hline 4. & Kepala Bidang Akuntansi Pelaporan Keuangan & 1 \\
\hline 5 & Kepala Sub Bidang Revisi Anggaran & 1 \\
\hline 6. & Kepala Sub Bidang Pelayanan Perbendaharaan & 1 \\
\hline 7. & $\begin{array}{l}\text { Kepala Sub Bidang Evaluasi Pertanggungjawaban } \\
\text { Keuangan }\end{array}$ & 1 \\
\hline 8. & $\begin{array}{l}\text { Kepala Sub Bidang Anggaran Belanja Tidak } \\
\text { Langsung dan Belanja Langsung }\end{array}$ & 1 \\
\hline 9. & Kepala Sub Bidang Pelaporan Keuangan & 1 \\
\hline 10. & Kabid Pengelolaan Aset & 1 \\
\hline 11. & Kasubbag Keuangan & 1 \\
\hline 12. & Kasubbag Program & 1 \\
\hline 13. & Kasubbag Umum dan Kepegawaian & 1 \\
\hline 14. & Kasubbid Perolehan dan Penghapusan Aset & 1 \\
\hline 15. & Kasubbid Kas dan Penerimaan PPKD & 1 \\
\hline 16. & Kasubbid Pengeluaran PPKD & 1 \\
\hline 17. & Kasubbid Pendayagunaan dan Pengendalian Aset & 1 \\
\hline 18. & Kasubbid Akuntansi dan Sistem Informasi & 1 \\
\hline 19. & Kasubbid Pencatatan dan Pelaporan Aset & 1 \\
\hline 20. & Pelaksana & 21 \\
\hline \multicolumn{2}{|r|}{ Total } & 40 \\
\hline
\end{tabular}

Sumber Data: BPKAD Bungo, 2019 
Untuk mengukur kemajuan pencapaian tujuan dan sasaran kinerja perlu ditentukan indikatornya serta berbagai aspek. Dengan adanya indikator sebagai tolak ukur, kemajuan atau keberhasilan suatu organisasi dalam menyelesaikan atau tugas menyelesaikan pekerjaan dapat dinilai dari tahun ketahun untuk mengetahui keberhasilan atau sampai sejauh mana tujuan yang dapat dicapai oleh Badan Pengelola Keuangan dan Aset Daerah Kabupaten Bungo, dapat dijelaskan dengan tabel 1.3 dibawah ini :

\section{Absensi Sidik Jari (Fingerprint)}

Absensi adalah daftar kehadiran pegawai/karyawan/siswa/guru yang berisi jam datang dan jam pulang serta alasan atau keterangan kehadiran. Absensi ini berkaitan dengan penerapan disiplin yang ditentukan oleh masing-masing organisasi atau instansi. Menurut (Widyahartono, 2008) Absensi sidik jari (fingerprint) merupakan salah satu penerapan teknologi guna mencapai tujuan dalam rangka meningkatkankedisiplinan Kerja.

Menurut Heriawanto Faisal (dalam Ahmad 2006:26), pelaksanaan pengisian daftar hadir atau absensi secara manual (hanya berupa buku daftarhadir), akan menjadikan penghambat bagi organisasi untuk memantau kedisiplinan pegawai dalam hal ketepatan waktu kedatangan dan jam pulang pegawai setiap hari. Hal tersebut di khawatirkan akan membuat komitmen pegawai terhadap pekerjaan dan organisasi menjadi berkurang. Berkurangnya komitmen pegawai dalam bekerja akan berdampak pada motivasi dan kinerja pegawai yang semakin menurun.

\section{Disiplin Kerja Pegawai}

Menurut (Robbins, 2005) mengemukakan bahwa disiplin kerja pegawai adalah kesadaran dan kesediaan seseorang menaati semua peraturan instansi dan norma-norma sosial yang berlaku. Sedangkan Menurut G.R. Terry (2006:218), disiplin merupakan alat penggerak karyawan. Agar tiap pekerjaan dapat berjalan dengan lancar, maka harus diusahakan agar ada disiplin yang baik. Menurut S.P Hasibuan, kedisiplinan adalah kesadaran dan kesediaan seseorang menaati semua peraturan instansi dan norma-norma sosial yang berlaku.

Menurut Mangkunegara(2011:29) mengemukakan bahwa bentuk disiplin kerja, yaitu :

1. Disiplin preventif, merupakan suatu upaya untuk menggerakan pegawai untuk mengikuti dan mematuhi pedoman kerja, aturanaturan yang telah digariskan oleh perusahaan.

2. Disiplin korektif, merupakan suatu upaya untuk menggerakan pegawai dalam suatu peraturan dan mengarahkan untuk tetap mematuhi peraturan sesuai dengan pedoman yang berlaku pada perusahaan.

3. Disiplin progresif, merupakan kegiatan yang memberikan hukuman-hukuman yang lebih berat terhadap pelanggaranpelanggaran yang berulang.

\section{Kinerja}

Kinerja berasal dari kata Job Performance yang berarti prestasi kerja yang dicapai oleh seseorang. Kinerja dinyatakan baik dan sukses apabila tujuan yang di inginkan dapat tercapai dengan baik. Robbins (2006), mengatakan bahwa Kinerja pegawai yang dilakukan oleh pegawai untuk membuktikan dirinya hadir atau tidak hadir dalam bekerja disuatu instansi berupa buku daftar hadir

Menurut Rivai (2011:554),Kinerja merupakan perilaku nyata yang ditampilkan setiap orang sebagai prestasi kerja yang dihasilkan oleh karyawan sesuai dengan perannya dalam perusahaan. 
Dari kedua definisi di atas dapat disimpulkanbahwa kinerja adalah hasil kerja yang dicapai oleh pegawai atau karyawan.

\section{METODOLOGI PENELITIAN}

mengetahui nilai variabel mandiri, baik satu variabel atau lebih (independen) tanpa membuat perbandingan, atau menghubungkan dengan variabel yang lain.

Adapun metode analisis data penelitian kuantitatif menurut Sugiyono (2013) yaitu metode penelitian yang berlandaskan pada filsafat positivisme, digunakan untuk meneliti pada populasi atau sampel tertentu, teknik pengambilan sampel pada umumnya dilakukan secara random, pengumpulan data menggunakan instrument penelitian, analisis data bersifat kuantitatif/statistik dengan tujuan untuk menguji hipotesis yang telah ditetapkan.
Jenis penelitian yang digunakan dalam penelitian ini adalah penelitian deskriptif dengan pendekatan kuantitatif. Menurut Sugiyono (2012) penelitian deskriptif yaitu penelitian yang dilakukan untuk HASIL PENELITIAN DAN PEMBAHASAN

\section{Hasil Uji t (Parsial)}

Uji-t dalam penelitian ini dilakukan dengan tingkat signifikan $\alpha 0,05$ sementara nilai $t_{\text {tabel }}$ pada $\alpha 0,05: 2=$ (uji dua sisi) dengan derajat kebebasan atau degree of freedom $\mathrm{df}=\mathrm{n}-\mathrm{k}-1$ atau 40-2-1=37 (n adalah jumlah responden dan $\mathrm{k}$ adalah jumlah variabel independen), diperoleh $t$ tabelnya adalah 2,02619. Maka dapat disimpulkan terdapat pengaruh signifikan secara individual masing - masing variabel. Nilai t tabel tersebut selanjutnya dibandingkan dengan nilai t hitung yang diperoleh dengan bantuan SPSS Statistik Versi 24 seperti terlihat pada tabel berikut ini :

\section{Hasil Uji T ( Parsial )}

\begin{tabular}{|l|c|c|c|c|c|c|}
\hline \multicolumn{2}{|c|}{} & \multicolumn{2}{|c|}{$\begin{array}{c}\text { Unstandardized } \\
\text { Coefficients }\end{array}$} & $\begin{array}{c}\text { Standardized } \\
\text { Coefficients }\end{array}$ & & \\
\cline { 3 - 6 } \multicolumn{2}{|c|}{ Model } & B & $\begin{array}{c}\text { Std. } \\
\text { Error }\end{array}$ & Beta & T & Sig. \\
\hline 1 & (Constant) & $-11,177$ & 8,191 & & $-1,365$ &, 181 \\
& TOTAL X1 &, 311 &, 198 &, 177 & 1,575 &, 124 \\
& TOTAL X2 & 1,878 &, 306 &, 691 & 6,143 &, 000 \\
\hline
\end{tabular}

a. Dependent Variable: TOTAL YSumber : Hasil Pengolahan Data dengan SPSS Versi 24

Berdasarkan tabel di atas dapat dilihat bahwa variabel Absensi Sidik Jari (Fingerprint) memiliki $\mathrm{t}$ hitung $1,575<\mathrm{t}$ tabel 2,02619 yang mempunyai nilai signifikan $0,000>0,05$ menunjukkan bahwa Absensi Sidik Jari (Fingerprint)tidak berpengaruh secara signifikan terhadap kinerjapegawai pada Kantor Badan Pengelola Keuangan dan Aset Daerah Kabupaten Bungo.

Dan berdasarkan tabel di atas juga dapat dilihat bahwa variabel disiplin kerja $t$ hitung $(6,143)>(2,02619)$ yang mempunyai nilai signifikan 0,001 $<0,05$ menunjukkan bahwa disiplin kerja berpengaruh secara signifikan terhadap kinerja pegawai pada Kantor Badan Pengelola Keuangan dan Aset Daerah Kabupaten Bungo.

\section{Uji Signifikansi Simultan (Uji F)}

Uji $F$ dalam penelitian ini digunakan statistik F (Uji F). Jika F-hitung < F-tabel maka Ho diterima atau $\mathrm{Ha}$ ditolak, sedangkan jika F-hitung > F-tabel maka Ho ditolak dan Ha diterima. Jika tingkat signifikansi dibawah 0,05 maka Ho ditolak 
Hasil Uji Simultan (Uji F Statistik)

\begin{tabular}{|c|c|c|c|c|c|c|}
\multicolumn{8}{|c|}{ ANOVA $^{\text {a }}$} \\
\hline \multirow{2}{*}{1} & Model & $\begin{array}{c}\text { Sum of } \\
\text { Squares }\end{array}$ & Df & $\begin{array}{c}\text { Mean } \\
\text { Square }\end{array}$ & F & Sig. \\
\hline & Regression & 604,187 & 2 & 302,093 & 28,889 &, $000^{\text {b }}$ \\
& Residual & 386,913 & 37 & 10,457 & & \\
& Total & 991,100 & 39 & & & \\
\hline
\end{tabular}

a. Dependent Variable: TOTAL_Y

b. Predictors: (Constant), TOTAL_X2, TOTAL_X1

Pada Tabel diatas mengungkapkan bahwa nilai F-hitung adalah 28,889 dengan tingkat signifikansi 0,000 lebih besar dari nilai $F$ tabel yakni 3,25. Dengan tingkat kesalahan $\alpha=0,05 \%$

Berdasarkan pengujian hipotesis jika $\mathrm{F}$ hitung $>\mathrm{F}$ tabel dan tingkat signifikansinyya $(0,000<0,05)$, menunjukkan bahwa variabel bebas (Penerapan Absensi Sidik Jari (Fingerprint)dan Disiplin Kerja) secara serempak berpengaruh Positif terhadap variabel terikat (Kinerja pegawai) Pada
Badan Pengelola Keuangan dan Aset Daerah Kabupaten Bungo.

\section{Uji Koefisien Determinasi}

Koefisien Determinasi ganda $\left(R^{2}\right)$ digunakan untuk melihat seberapa besar kontribusi pengaruh variabel independen yang terdiri dari penerapan absensi sidik jari (fingerprint) dan disiplin kerja secara simultan terhadap variabel dependen yakni kinerja pegawai pada Badan Pengelola Keuangan dan Aset Daerah Kabupaten Bungo. Dapat dilihat pada tabel model summary berikut ini :

\begin{tabular}{|l|c|r|r|r|}
\hline & & & Model Summary \\
Model & $\mathrm{R}$ & R Square & $\begin{array}{c}\text { Adjusted R } \\
\text { Square }\end{array}$ & $\begin{array}{c}\text { Std. Error of } \\
\text { the Estimate }\end{array}$ \\
\hline 1 &, $781^{\mathrm{a}}$ &, 610 &, 589 & 3,234 \\
\hline
\end{tabular}

a. Predictors: (Constant), TOTAL_X2, TOTAL_X1

b. Dependent Variable : Total_Y Sumber : Hasil Pengolahan Data dengan SPSS Versi 24

Berdasarkan output Model Summary di atas dapat dilihat nilai $R$ Squaresebesar 0.610 atau

, $0 \%$ besarnya nilai tersebut menunjukkan proporsi pengaruh yang dapat dijelaskan oleh variabel penerapan absensi sidik jari (fingerprint)dan disiplin kerja secara bersama-sama terhadap besarnya variasi (naik turun) variabel terikat. Dimana variabel terikat (Y) dapat dijelaskan oleh kedua variabel bebas sebesar 61,0\% sedangkan sisanya sebesar 39,0\% dipengaruhi oleh faktor lain yang tidak diteliti dalam penelitian.

\section{PENUTUP}

\section{Kesimpulan}

Berdasarkan data yang diperoleh dari hasil analisis dapat ditarik kesimpulan sebagai berikut : 
1. Hasil dari uji $\mathrm{t}$ menunjukkan bahwa Absensi Sidik Jari (Fingerprint)tidak berpengaruh secara signifikan terhadap kinerjapegawai pada Kantor Badan Pengelola Keuangan dan Aset Daerah Kabupaten Bungo dimana nilai t hitung 1,575 $<$ t tabel 2,02619.

2. Hasil uji t untuk variabel Disiplin Kerja menunjukkan bahwa disiplin kerja berpengaruh secara signifikan terhadap kinerja pegawai pada Kantor Badan Pengelola Keuangan dan Aset Daerah Kabupaten Bungo dimana nilai t hitung $(6,143)>(2,02619)$.

3. Hasil dari uji f menunjukkan bahwa F-hitung adalah 28,889 dengan tingkat signifikansi 0,000 lebih besar dari nilai $\mathrm{F}$ tabel yakni 3,25. Dengan tingkat kesalahan $\alpha=0,05 \%$. Berdasarkan pengujian hipotesis jika $\mathrm{F}$ hitung $>\mathrm{F}$ tabel dan tingkat signifikansinyya $(0,000<0,05)$, menunjukkan bahwa variabel bebas (Penerapan Absensi Sidik Jari (Fingerprint) dan Disiplin Kerja) secara serempak berpengaruh Positif terhadap variabel terikat (Kinerja pegawai) Pada Badan Pengelola Keuangan dan Aset Daerah Kabupaten Bungo.

4. Hasil uji koefisien determinasi $\left(R^{2}\right)$ dapat dilihat nilai $R$ Square sebesar 0.610 atau $61,0 \%$ besarnya nilai tersebut menunjukkan proporsi pengaruh yang dapat dijelaskan oleh variabel penerapan absensi sidik jari (fingerprint) dan disiplin kerja secara bersama-sama terhadap besarnya variasi (naik turun) variabel terikat. Dimana variabel terikat (Y) dapat dijelaskan oleh kedua variabel bebas sebesar 61,0\% sedangkan sisanya sebesar $39,0 \%$ dipengaruhi oleh faktor lain yang tidak diteliti dalam penelitian.

\section{SARAN}

Berdasarkan kesimpulan diatas penulis memberikan saran sebagai berikut :

1. Kepada pegawai Badan Pengelola Keuangan dan Aset Daerah Kabupaten Bungo agar lebih mengefektifkan pelaksanaan prosedur Absensi Sidik Jari (Fingerprint) sehingga dapat meningkatkan kedisiplinan pribadi masing-masing pegawai, tercipta nya kondisi kerja yang baik seperti datang dan pulang tepat waktu serta taat dan patuh dengan peraturan-peraturan yang telah ditetapkan pada instansi pemerintahan tersebut.

2. Pada instansi pemerintahan tersebut diharapkan untuk mengevaluasi kembali pembagian waktu istirahat, agar tidak terjadinya penyimpangan seperti halnya jika istirahat dimanfaatkan untuk beristirahat dan tidak menambah waktu istirahat. Hal tersebut dilakukan agar tidak terjadinya kekantor hanya untuk absensi sidik jari (Fingerprint) dan kemudian pergi meninggalkan kantor. Kemudian terciptanya kedisiplinan kerja pegawai yang baik dan dapat menciptakan jam kerja yang lebih efektif dan efisien dalam meningkatkan standar pekerjaanya untuk mencapai target.

3. Para peneliti selanjutnya yang akan mengkaji lebih dalam tentang penelitian yang sama, diharapkan agar penelitian ini dapat menjadi salah satu informasi yang dapat digunakan untuk penelitian selanjutn

\section{DAFTAR PUSTAKA}

Arikunto, Suharsimi. 2006. Metodologi Penelitian, Yogyakarta: Bina Aksara.

Hasibuan, Malayu. 2012. Manajemen Sumber Daya Manusia: edisi revisi,Jakarta: Bumi Aksara.

Hylenarti Hertyana. 2016. Pengaruh Sistem absensi Fingerprint Terhadap Kinerja Karyawan Pada Pt. Deltacomsel Indonesia: Jurnal Teknik Komputer AMIK BSI, Program Studi Sistem Informasi STMIK Nusa Mandiri Jakarta Vol.II, No.2 
Kumorotomo,Wahyudi\&Subando Agus Margono.1994. Sistem InformasiManajemen dalam Organisasi-organisasi Publik, Yogyakarta: Gadjah Mada University Press.

Lexy. J. Moleong. Metode Penelitian Kualitatif, Remaja Rosdakarya, Bandung, 1991.

Lia Sepda Kristin. 2016. Pengaruh Penerapan Presensi Sidik Jari (Fingerprint) Terhadap Kinerja Guru Melalui Motivasi Kerja Di SMA Negeri 5 Malang: Jurnal Pendidikan Bisnis dan Manajemen, Volume 2, Nomor 3.

Maeyasari, Erna. 2012. Pengaruh Efektivitas Penerapan Absensi Finger Print terhadap Disiplin Pegawai Negeri Sipil di Sekretariat Daerah Kabupaten Lebak. Skripsi. Serang: Universitas Sultan Ageng Tirtayasa.

Martono, Nanang. 2016. Metode Penelitian Kuantitatif: Analisis Isi dan Analisis Data Sekunder,Jakarta: Rajawali Pers.

Nur Alam. 2013. Perancangan Sistem Informasi Pendukung Laporan AbsensiElektronik BBPPKI Makassar.Makassar: Jurnal Penelitian

Komunikasi,Informatika dan Media Massa (PEKOMMAS). Vol. 16, No.1: 61-72.

Peraturan Pemerintah Nomor 53 Tahun 2010 tentang Disiplin Pegawai Negeri Sipil atau Aparatur Sipil Negara.

Robbins, Stephen P. 1994, Teori Organisasi: Struktur, Desain dan Aplikasi, Jakarta: Arcan.

Ria Kurniati. 2018. Pengaruh Penerapan Sistem Absensi Elektronik (Finger Print Scanner) Terhadap Disiplin Kerja Pegawai NegeriSipil pada Dinas Kebersihan dan Pertamanan Kota Medan. Skripsi. Medan: Univeristas Sumatera Utara.

Risfa Fadila. 2019. Pengaruh Penerapan Sistem Absensi Fingerprint Terhadap Disiplin Pegawai Pada Markas Komando Direktorat Pengamanan badan Pengusaha Batam: Jurnal Of Business Administration Vol.3, No.1 Halaman 53-63 eISSN:2548-9909

Siagian, Sondang P. 2008. Manajemen Sumber Daya Manusia, Ed. 1, Cet.16. Jakarta: Bumi Aksara.

Saydam, Gouzali. 1996, Manajemen Sumber Daya Manusia (Human Resources Management) Suatu Pendekatan Mikro (Dalam Tanya Jawab), Jakarta:Djambatan.

Sinambela, Lijan Poltak.2012. Kinerja Pegawai: Teori Pengukuran dan Implikasi, Yogyakarta: Graha Ilmu.

Sugiyono. Metode Penelitian Administrasi, Alfabeta, Bandung, 1998.

Sunyoto, Danang. 2007. Analisis Regresi dan Korelasi Bivariat Ringkasan dan Kasus, Yogyakarta: Amara Books.

Metode Penelitian Kuantitatif, Kualitatif dan $R \& D$, Alfabeta, Bandung. 2008 